\title{
Endoscopic extended transsphenoidal resection of tuberculum sellae meningiomas: nuances of neurosurgical technique
}

\author{
Charles Kulwin, M.D., ${ }^{1}$ Theodore H. Schwartz, M.D., ${ }^{2}$ \\ and Aaron A. Cohen-Gadol, M.D., M.Sc. ${ }^{1}$ \\ ${ }^{1}$ Department of Neurological Surgery, Indiana University, and Goodman Campbell Brain and Spine, \\ Indianapolis, Indiana; and ${ }^{2}$ Departments of Neurological Surgery, Otolaryngology, and Neurology, Brain \\ and Spine Center, Brain and Mind Research Institute, Weill Cornell Medical College, NewYork-Presbyterian \\ Hospital, New York, New York
}

\begin{abstract}
Over the past decade, advances in endoscopic microsurgical techniques have resulted in an increasingly aggressive endonasal approach to tumors of the midline skull base. Meningiomas of the tuberculum sellae are often closely associated with cerebrovascular structures, and their removal has traditionally required a transcranial approach. An endonasal approach offers many advantages, including early tumor devascularization and tumor debulking (without manipulation of the optic apparatus), direct access to the medial optic canal, and a minimal-access corridor.

Although recent articles have focused on techniques for reaching and approaching the area of the pathology (how to get there), the authors of this report discuss the technical nuances of endoscopic microsurgery when the operator is already "there." They describe their 6-step technique for endoscopic skull base bone removal, tumor dissection/resection, and closure. They also augment their description with elaborate illustrations. (http://thejns.org/doi/abs/10.3171/2013.8.FOCUS13338)
\end{abstract}

KEY WoRdS
microsurgery $\stackrel{\begin{array}{c}\text { endoscopic } \\ \text { technique }\end{array}}{\bullet}$ transnasal approach $\quad$ meningioma

$\mathrm{T}$ He versatility of endoscopic endonasal surgery for approaching suprasellar lesions has been increasingly recognized over the past decade. ${ }^{5}$ Despite initial trepidation about manipulating supradiaphragmatic areas of pathology through the nose, a purely endoscopic endonasal approach to purely suprasellar lesions such as meningiomas of the anterior fossa has been demonstrated to be both effective and safe in the hands of experienced surgeons..$^{6,9,15,21}$ Since the first descriptions of this technique for resection of anterior fossa meningiomas that involve the optic nerves, ${ }^{11,12}$ tuberculum sellae meningiomas have been an attractive target: a subchiasmatic approach to a subchiasmatic lesion.

However, tuberculum sellae meningiomas present a surgical excision challenge, ${ }^{23}$ in part because of the adjacent and involved critical structures that can be placed at risk during a transcranial approach, especially the optic nerves, carotid and anterior cerebral arteries, the pituitary gland and stalk, and the hypothalamus. ${ }^{24}$ An endoscopic endonasal approach theoretically avoids similar manipulation by approaching the meningioma through its dural base, thereby minimizing retraction of the optic nerve and decreasing the risk for postoperative visual deterioration. ${ }^{1,27}$ The other benefits to endoscopic endonasal surgery-minimal inva- siveness leading to improved patient comfort and shorter hospitalizations-are often criticized as being offset by a higher rate of CSF leakage. ${ }^{2}$ However, modern closure techniques, when performed by experienced hands, result in very low rates of CSF leakage for suprasellar lesions, ${ }^{18}$ and recent data suggest that for a select group of lesions, the endoscopic endonasal approach might be optimal and should be entertained as having broader applications. ${ }^{7}$

As demonstrated by the higher complication rates reported for those early in their endoscopic neurosurgical careers, the learning curve can be steep, particularly for neurosurgeons not well trained in endonasal endoscopy. ${ }^{13,20,25}$ To flatten the learning curve and clarify some of the technical nuances involved in successful removal of tuberculum sellae meningiomas, we present a purely technical descriptive study and provide elaborate illustrations prepared through 3D graphic models. The purpose of this report is to familiarize the novice endonasal surgeon with a 6 -step process for removing these meningiomas.

\section{Patient Selection}

Given the narrow corridor provided by this approach, patient selection is of utmost importance. In the sagittal 
plane, endoscopic endonasal surgery can reach from the frontal sinus down to the craniocervical junction. Anatomical limitations exist in the coronal plane and vary as one moves from a rostral to a caudal direction. ${ }^{26}$ Likewise, although the endonasal corridor may be narrow at certain coronal planes, it is possible to see and remove tumor lateral to these limits because of the endoscope's fish-eye field of view, the existence of angled endoscopes, and corresponding angled instrumentation. There are no absolute limitations to lesion size for endoscopic endonasal surgery; however, lesions smaller than $4 \mathrm{~cm}$ are considered ideal. Although the lateral limits of the corridor are formed first by the lamina papyracea, then the carotid siphon in the cavernous sinus, then the lateral opticocarotid recess around the sella and the carotid bifurcation in the suprasellar cistern, tumor that extends slightly beyond these limits can often be rolled toward the center after adequate internal debulking.

Tuberculum sellae meningiomas derive their principal dural base from the dura of the tuberculum sellae, and their dural attachment can extend inferiorly toward the anterior wall of the sella turcica and diaphragma sellae and anteriorly toward the limbus and posterior planum sphenoidale. This growth pattern results in displacement of the optic chiasm posteriorly and/or superiorly, ${ }^{17}$ displacement of the pituitary stalk and sellar contents posteriorly, and displacement of the optic nerves laterally, particularly in the not uncommon case of tumor growth into the optic canals (Fig. 1). Chiasmal compression and optic canal invasion result in visual deterioration and early discovery of the meningioma. Therefore, tuberculum sellae meningiomas are often detected while at a size smaller than other anterior fossa meningiomas and render themselves more amenable to endoscopic endonasal surgery. Typical case series have reported mean diameters of less than $3 \mathrm{~cm} \cdot \cdot^{14,19}$

Key considerations for endoscopic endonasal surgery include sphenoid sinus and tuberculum/suprasellar notch anatomy, relative position of the optic chiasm and pituitary stalk, parasellar extension of the tumor or encasement of neurovascular structures, and degree of tumor calcification. Although involvement of the optic canals was initially thought to be a contraindication for endoscopic endonasal surgery, ${ }^{6}$ adequate and safe exploration and resection of intracanalicular meningiomas has been demonstrated. ${ }^{17}$ Indeed, exploration and graded opening of the medial optic canal is mandatory for ensuring complete tumor removal when canal involvement is demonstrated on preoperative high-resolution MR images.

Debate exists over the need for a cortical cuff around the tumor, meaning that no arterial branch is directly touching the tumor. ${ }^{26}$ Although a cortical cuff certainly facilitates tumor dissection, its presence is not mandatory, and careful extracapsular microdissection of vessels off the tumor capsule is possible and often required. Generally, the most amenable lesions are those that are smaller and mostly midline, those that maintain their arachnoid place as evidenced by a lack of edema in the brain, those that do not encase neurovascular structures, and those that have a well-aerated sphenoid sinus for access and closure. Patient selection remains one of the most important

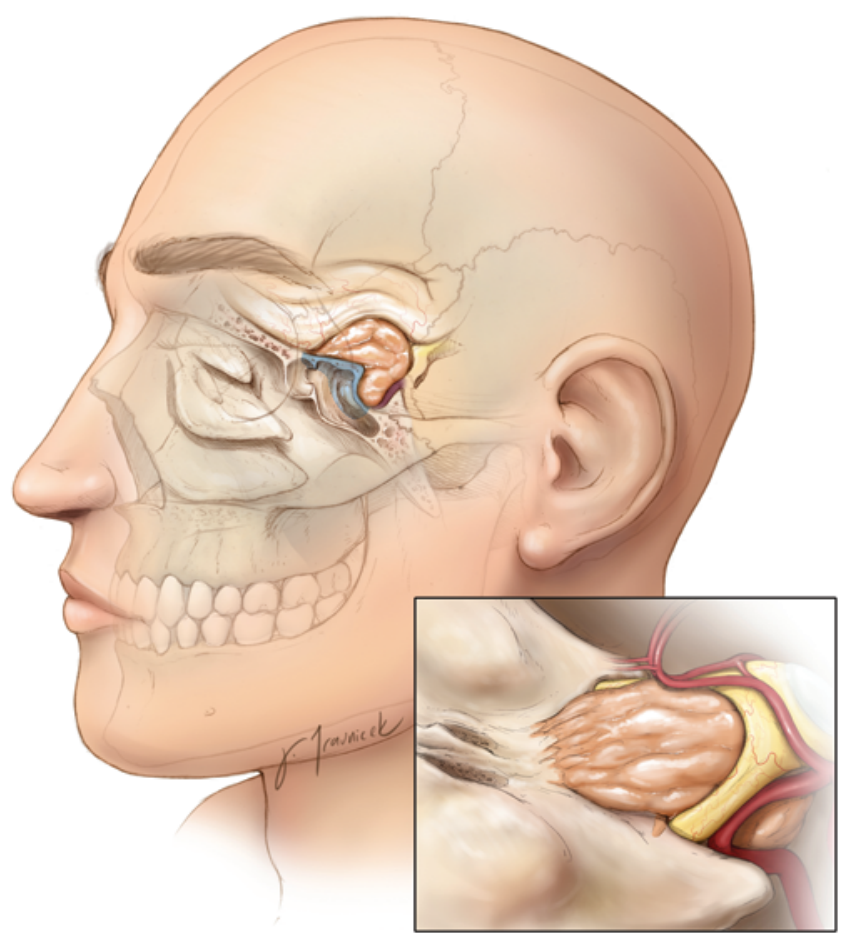

FIG. 1. Lateral see-through illustration of a typical meningioma of the tuberculum sellae. The extent of bone removal underlying the typical dural attachment is highlighted in blue. Note the anterior extension along the planum sphenoidale and the inferior extension into the sella turcica. Inset: Superolateral view demonstrating the typical planum attachment, optical canal invasion, and displacement of the optic apparatus and surrounding vasculature. Reproduced with permission from Aaron A. Cohen-Gadol: The Neurosurgical Atlas.

factors for achieving good outcome; overzealous use of endoscopic endonasal surgery for poorly selected patients often leads to disappointing results.

\section{Operative Technique}

\section{Step 1: Approach}

The details of the approach are well described ${ }^{3-5,11,17,28}$ and will be only briefly reviewed here to emphasize variations of technique. The patient is positioned supine, either in pin fixation or a horseshoe headrest, depending on whether cranial manipulation is desired. After induction of general anesthesia, frameless neuronavigation is registered by using CT and /or MRI. Routine nasal mucosal preparation is used, and a suitable donor site is prepared. We suggest fascia lata for the gasket seal. Others have recommended fat; however, any placement of intracranial fat will obscure postoperative imaging of residual tumor. We routinely place a lumbar drain, but others do not feel that this is mandatory.

The preparation of a Hadad-Bassagasteguy vascularized nasoseptal flap ${ }^{10}$ and an endoscopic approach to the sphenoid sinus through both nares has been described. ${ }^{15,17,21}$ The neurosurgeon operates bimanually through 1 or both nares while an assistant either provides dynamic endoscopic visualization using a combination of $0^{\circ}$ and $30^{\circ}$ endoscopes or the endoscope is placed on a scope holder that 


\section{Endoscopic resection of tuberculum sellae meningiomas}

can be frequently manipulated during the surgery. It is important to note that during bimanual microsurgery through the nares, if the $0^{\circ}$ scope limits the working angle of the microsurgical instruments, the $30^{\circ}$ scope can be used to move the head of the endoscope out of the way while providing adequate illumination and visualization. Likewise, the view upward and to the sides is facilitated with angled endoscopes.

An extremely wide sphenoidotomy is performed with complete removal of the rostrum and flattening of the floor of the sphenoid to aid with placement of the nasoseptal flap. The lateral limits of the corridor should not be restricted by the anterior wall of the sphenoid but rather by the lateralized turbinates. In some patients, the middle and/or superior turbinates can be removed to increase the exposure, particularly on the patient's left side, to make room for the endoscope. Bilateral posterior ethmoidectomies are essential for providing a clear view of the an- terior extent of the planum sphenoidale. However, overly exuberant removal of mucosa from the roof of the nasal cavity can result in permanent anosmia. After removal of the posterior sphenoid sinus mucosa, which must be completely removed to prevent mucocele formation behind the nasoseptal flap, the bony anatomy can be well visualized (Fig. 2).

Key bony landmarks define the relevant anatomy: the medial opticocarotid recess defines the lateral edge of the sella, the medial edge of the cavernous sinus, and the inferior and medial borders of the optic canal superiorly; the suprasellar notch is the endosinus analog to the tuberculum sellae, and the clival recess defines the inferior/posterior sellar extent. Neuronavigation identifies the extent of the tumor and thus the requisite bone removal. A high-speed drill with a round diamond bit is used to remove bone over the anterosuperior sella just below the superior intercavernous sinus, extending up to the tuber-

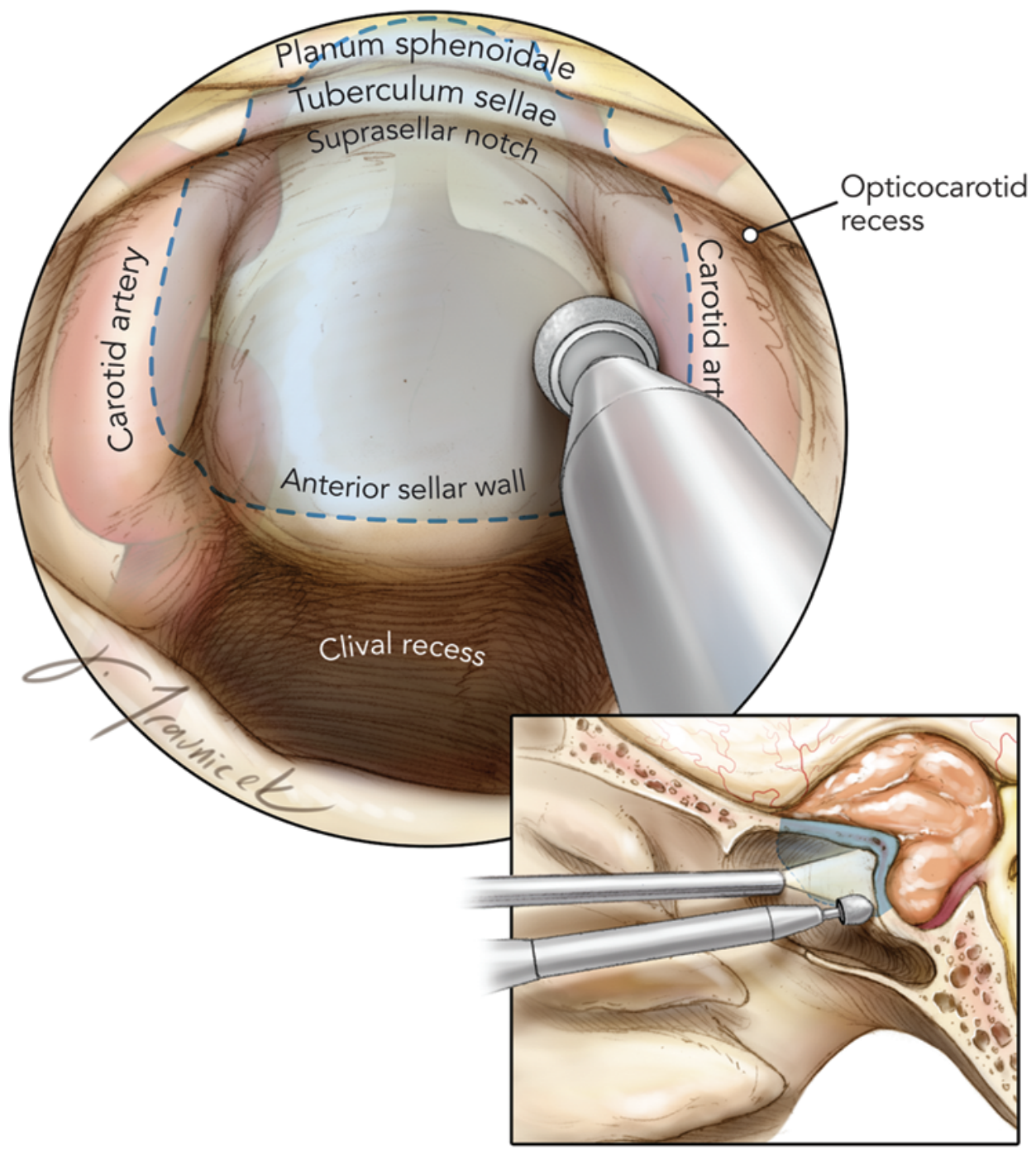

Fig. 2. Upper: Anterior endoscopic view of the posterior wall of the sphenoid sinus after removal of the mucosa revealing the relevant bony anatomy. Note the anterior sellar wall centrally, bilateral opticocarotid recesses laterally, and the suprasellar notch superiorly. The area of bone removal is shaded and outlined. Lower: Lateral view demonstrating superoinferior extent of bone removal and trajectory of endoscope and high-speed drill. Reproduced with permission from Aaron A. Cohen-Gadol: The Neurosurgical Atlas. 


\section{Kulwin, T. H. Schwartz, and A. A. Cohen-Gadol}

culum, lateral to the medial opticocarotid recesses and forward along the planum to the anterior extent of the tumor and its dural tail.

Unnecessary extensive bone removal leads to an increased risk for postoperative CSF leakage by making skull base reconstruction more challenging at the end of the operation. Therefore, bone removal over the uninvolved pituitary gland is minimized unless the tumor invades into the sella. If optic canal invasion has been identified on preoperative imaging, the medial optic canals should be removed to reach the anterior extent of the tumor within the canals. If no canal involvement is identified on preoperative imaging, the canals can be explored with an angled endoscope after the tumor is removed and opened only if tumor is seen within the canal. Nevertheless, the most frequent mistake of the novice surgeon is inadequate bone opening; to obtain a complete and safe resection that avoids blind pulling on an inadequately visualized tumor capsule, the entire base of the tumor must be exposed.

The dura is then opened sharply in a cruciate fashion after bipolar electrocautery has devascularized the dural base of tumor (Fig. 3). The intercavernous sinus is often compressed and does not bleed; however, it should be well cauterized before the dura is opened.

\section{Step 2: Internal Decompression and Anterosuperior Margin Dissection}

After the tumor is exposed, the next step is internal decompression. Before the lateral margins of the tumor can be seen and before the capsule can be safely mobilized for extracapsular dissection, the tumor must be internally decompressed. Early internal decompression also takes the

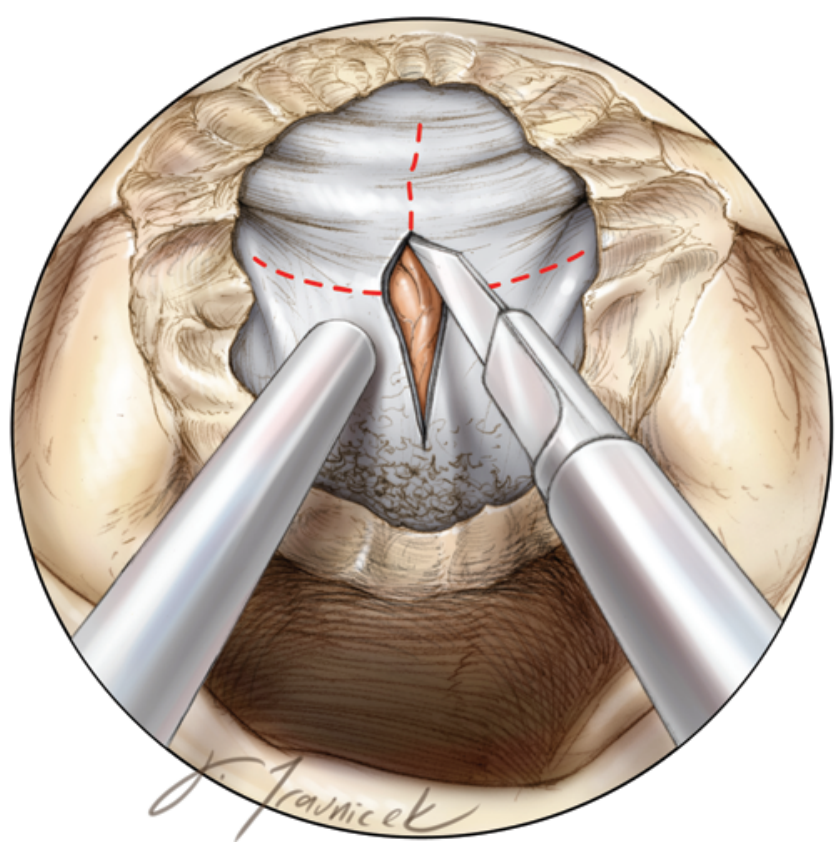

FIG. 3. The cruciate dural opening after removal of the tuberculum, posterior planum, and superior sella. The intercavernous sinus can be patent within the dura of the anterior sella and should be cauterized before incision. Reproduced with permission from Aaron A. Cohen-Gadol: The Neurosurgical Atlas. pressure off the optic chiasm and enables mobilization of the capsule later in the operation without placing the nerves at risk. Depending on the consistency of the tumor, internal decompression can be performed with bimanual suction, pituitary rongeurs, an ultrasonic aspirator, a Myriad system (NICO Corporation), or a Surgi-Max system (Elliquence, LLC) (Fig. 4). Internal decompression of the most anterior part of the tumor often requires using a $30^{\circ}$ scope to see in the anterosuperior direction.

For 5 reasons, it is helpful to reach and mobilize the anterior margin of the tumor early in the operation. First, doing so ensures that a sufficient amount of the planum has been removed for mobilizing the capsule. Second, the anterior capsule of the tumor is least likely to involve critical neurovascular structures and is therefore the easiest to dissect off the surrounding normal anatomic structures, namely the gyri recti (Fig. 5). Third, after the anterior margin is mobilized, one can work over the top of the tumor to reach the chiasm safely, rather than blindly through the center of the tumor. Fourth, after the surgeon has access over the top of the tumor, he or she can start the lateral dissection by using the margin of the tumor rather than trying to find the lateral margin through the center of the tumor. And fifth, after the anterior margin is reached, a substantial portion of the tumor can be decompressed safely. It is also important to maximize tumor decompression before the lateral and posterior dissection begins, which involves mobilization of the tumor capsule off the optic nerves and chiasm; the anterior cerebral, superior hypothalamic, and posterior cerebral arteries; and the pituitary stalk.

Often the first vascular structures encountered at this point are the $A_{2}$ branches and recurrent artery of Heubner. Generally, there is an arachnoid plane that can be used to dissect the vessels against the tumor capsule. Careful bimanual sharp dissection must be performed. If at any time the tumor bulk is compromising the operator's vision, additional internal decompression should be performed to facilitate extracapsular dissection. The superior dissection can then be continued to the level of the chiasm. The key to safe chiasmal decompression is avoiding any manipulation of the chiasm itself. Safe decompression can be performed by placing gentle traction on the tumor and rolling it off the chiasm by using sharp or gentle blunt dissection, when needed, to develop the plane between the tumor and the chiasm. This maneuver is often accomplished by using a $30^{\circ}$ scope, although if a sufficient amount of the superior pole of tumor has been removed, a $0^{\circ}$ scope can be used (Fig. 6). One of the most common causes of visual deterioration after endoscopic endonasal surgery is injury to the perforators of the optic chiasm. Careful preservation of all perforators will avoid postoperative visual complications.

\section{Step 3: Inferior Margin Dissection}

At this point, the remains of the tumor comprise its attachment to the inferior chiasm, the pituitary stalk and gland, the mammillary bodies, and the diaphragma sella. Because these structures are at the inferior margin of the tumor, a $0^{\circ}$ scope will enable adequate visualization while providing adequate working space for other instru- 

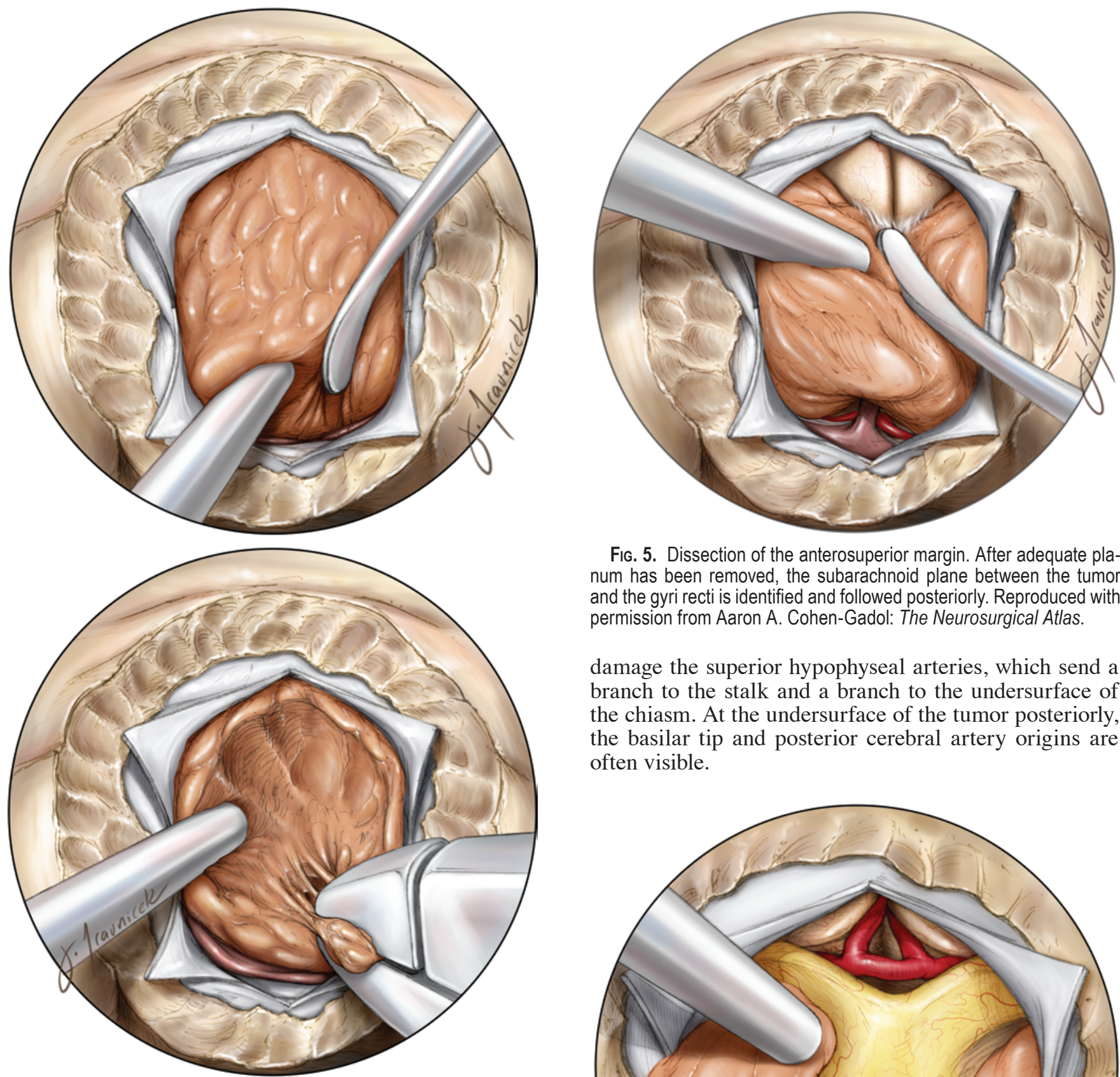

FIG. 5. Dissection of the anterosuperior margin. After adequate planum has been removed, the subarachnoid plane between the tumor and the gyri recti is identified and followed posteriorly. Reproduced with permission from Aaron A. Cohen-Gadol: The Neurosurgical Atlas.

damage the superior hypophyseal arteries, which send a branch to the stalk and a branch to the undersurface of the chiasm. At the undersurface of the tumor posteriorly, the basilar tip and posterior cerebral artery origins are often visible.

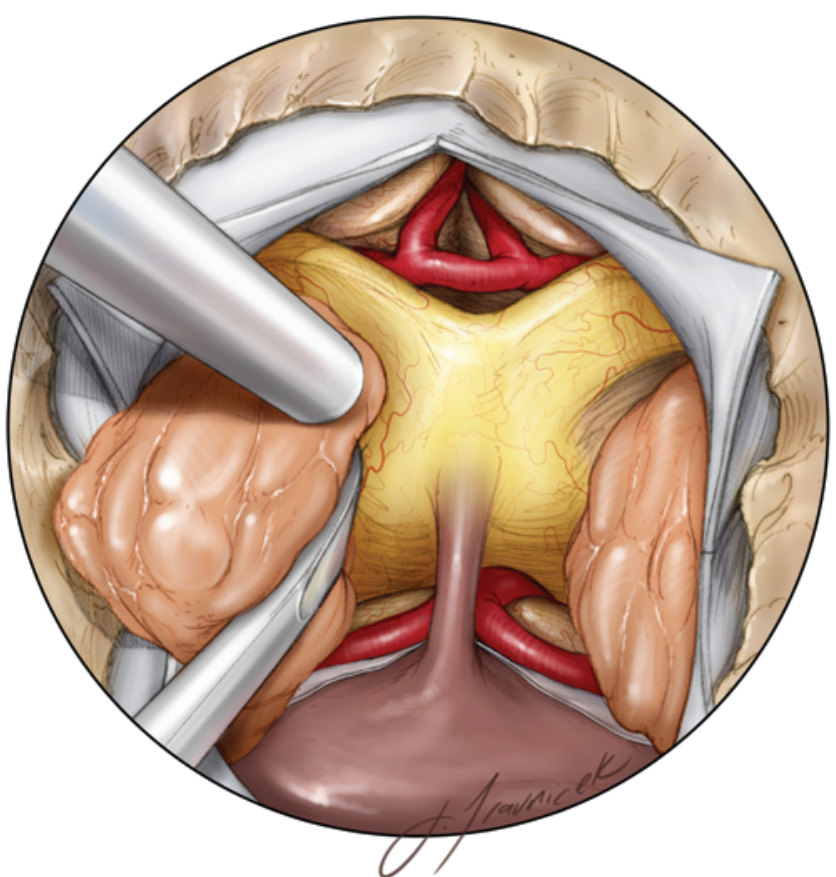

FIG. 6. Decompression of the optic chiasm. After maximal central debulking of the tumor, the superior margin is followed posteriorly, and the optic chiasm, medial optic nerves, and the anterior cerebral arteries are safely identified and decompressed. Reproduced with permission from Aaron A. Cohen-Gadol: The Neurosurgical Atlas. 


\section{Kulwin, T. H. Schwartz, and A. A. Cohen-Gadol}

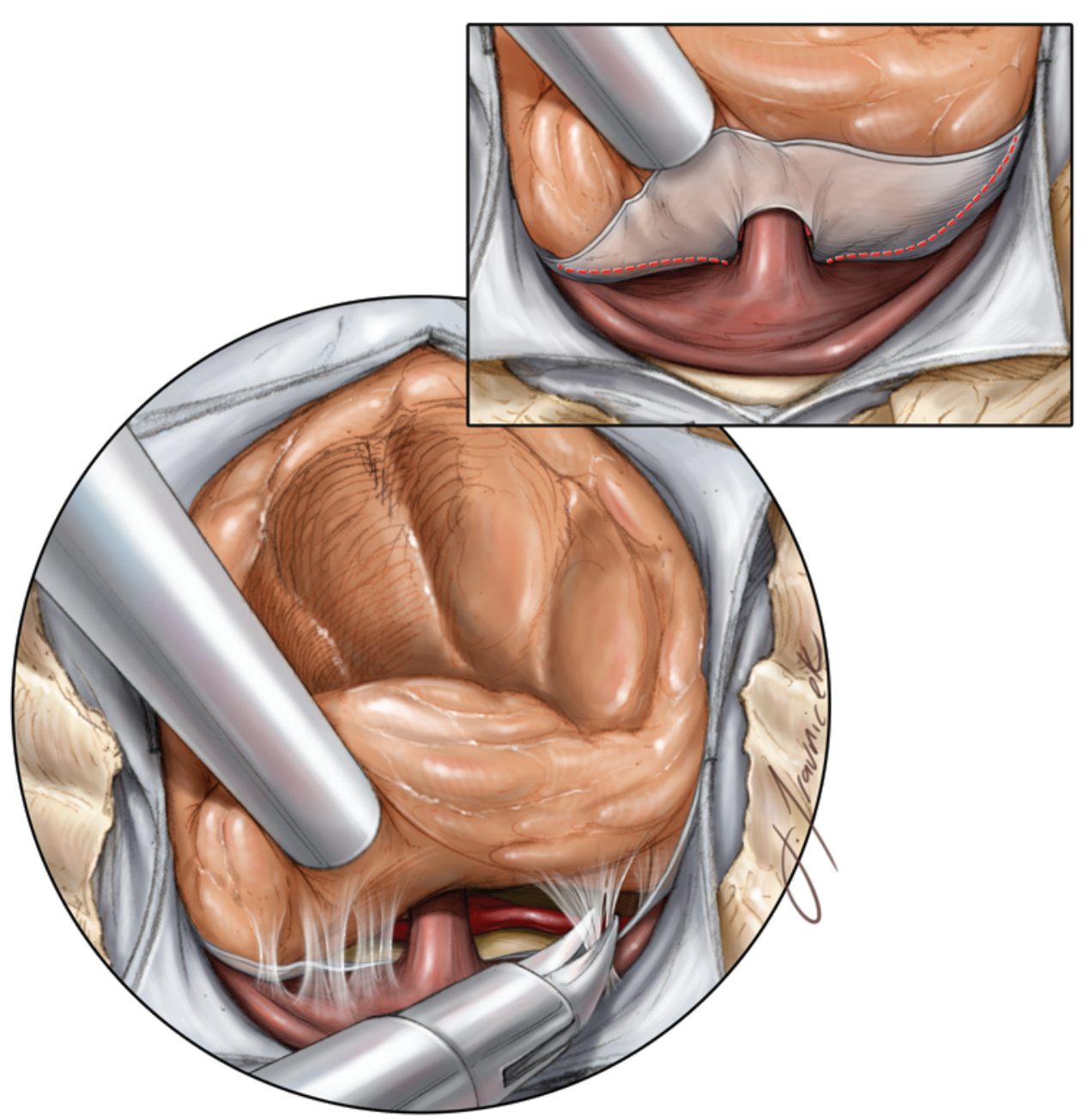

FIG. 7. Resection of involved diaphragm and inferior resection. Upper and Lower: If the tumor extends into the sella, involved diaphragm dura is identified, elevated, and sharply resected, and the inferior margin is followed in the subarachnoid plane to finish the central tumor removal off the distorted pituitary gland and stalk. The basilar apex and posterior cerebral arteries can usually be visualized. Tumor extension into the sella can be evaluated and resected. Reproduced with permission from Aaron $A$. Cohen-Gadol: The Neurosurgical Atlas.

\section{Step 4: Lateral Tumor Removal}

By following the superior margin of the tumor laterally, the operator can roll the lateral portion of the tumor into the debulked central cavity. A $30^{\circ}$ scope can be useful for seeing laterally beyond the bony opening and ensuring that no small vessels arising from the posterior communicating artery are adherent to the tumor. Blunt and sharp dissection can be used to dissect adherent vessels. The operator should avoid placing traction on any residual tumor attached to the optic nerves (Fig. 8). The optic nerves are followed laterally until the optic canal is reached just above the medial opticocarotid recess. The tumor is then rolled into the center of the resection cavity while the nerves or any perforating vessels are protected. If the tumor is not invading into the canal, then the lateral portion of the tumor below the optic nerves is removed. This portion of the tumor is medial to the posterior cerebral arteries and third cranial nerves, and care should be taken to preserve these structures and minimize their manipulation.

\section{Step 5: Optic Canal Exploration and Decompression}

If optic canal invasion was seen on preoperative MR images, the canal should have been drilled at the beginning of the operation. However, if canal invasion is seen during the operation, the canal should be widened for tumor removal. After the optic nerve trajectory is visualized, bone removal is extended along the optic canal with fine Kerrison rongeurs and thinned where needed with a high-speed drill (Fig. 9). The dura of the optic canal is then opened by using a sickle knife (Fig. 10). Because the ophthalmic artery runs inferior and medial to the nerve, the dura of the canal should be incised along its superior portion. A microDoppler ultrasonography probe can be useful for identifying the ophthalmic artery, although the artery's entry into the canal can often be easily seen at this point. The optic canal on each side can now be seen and inspected for any residual tumor, which is dissected off the nerve. To avoid compressing the optic nerve against the dural edge, the operator should not remove tumor fragments within the optic canal until after the canal has been opened (Fig. 11). 


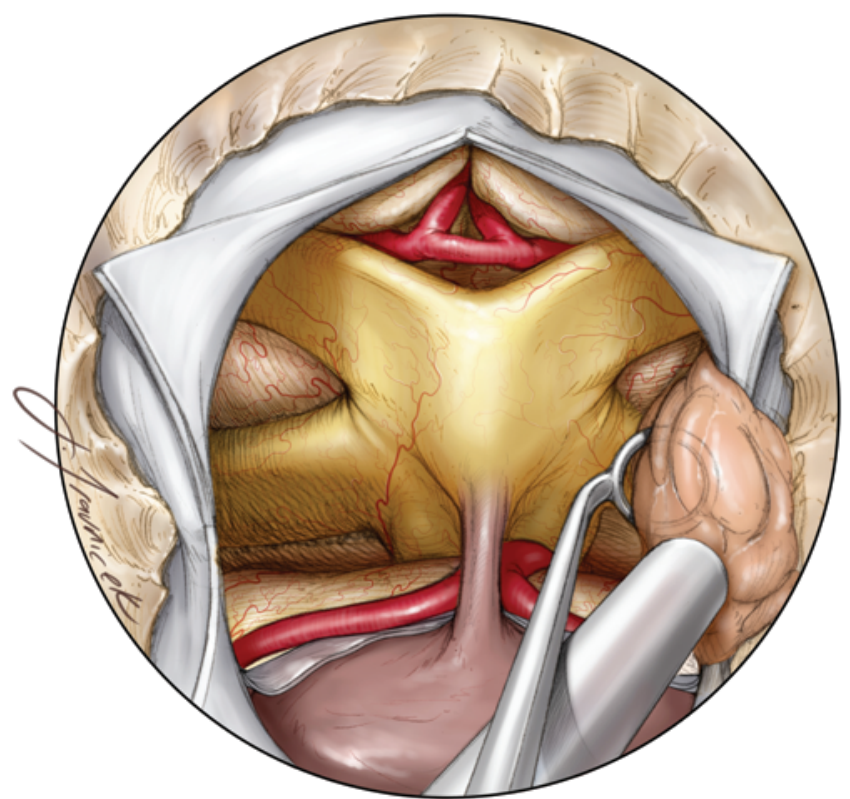

FIG. 8. Lateral tumor removal. After central removal is complete, the optic nerves can be visualized. Lateral tumor is gently rolled off the optic nerves into the central resection cavity. Care is taken to preserve adherent vessels and avoid manipulation of the optic nerves. An angled endoscope enables subsequent inspection of the optical canal for tumor invasion. Reproduced with permission from Aaron A. CohenGadol: The Neurosurgical Atlas.

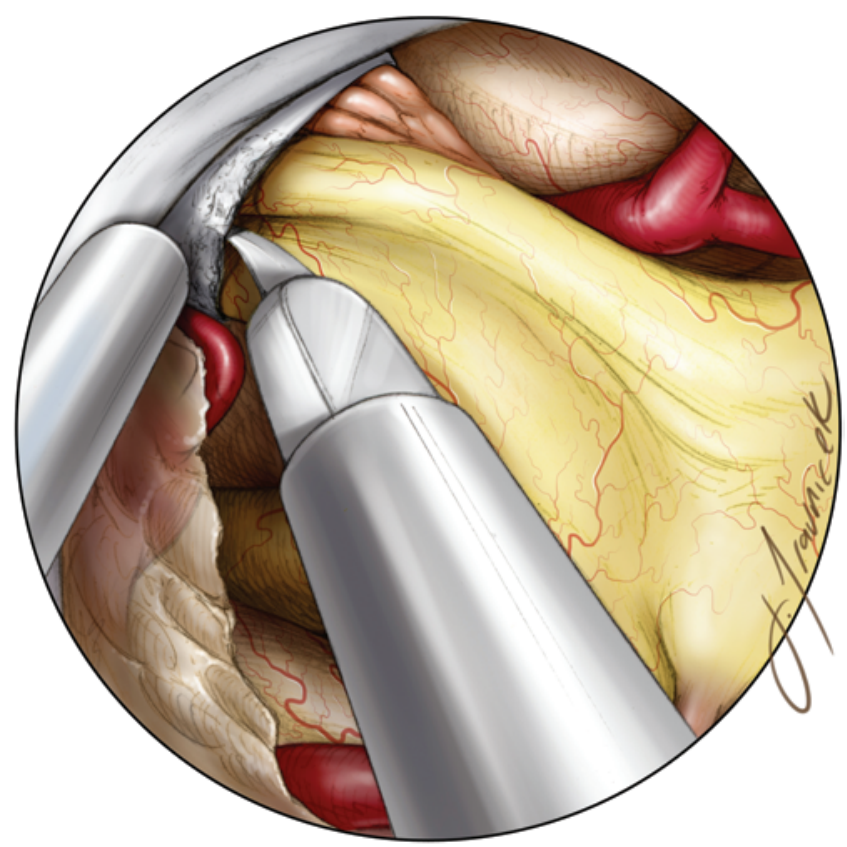

FIG. 9. Bony decompression of the optic canals. After the optic canal can be inspected, tumor involvement indicates a need for exploration and decompression of the optic nerves. The overlying bone is thinned with a high-speed drill and removed with fine Kerrison rongeurs. Reproduced with permission from Aaron A. Cohen-Gadol: The Neurosurgical Atlas.

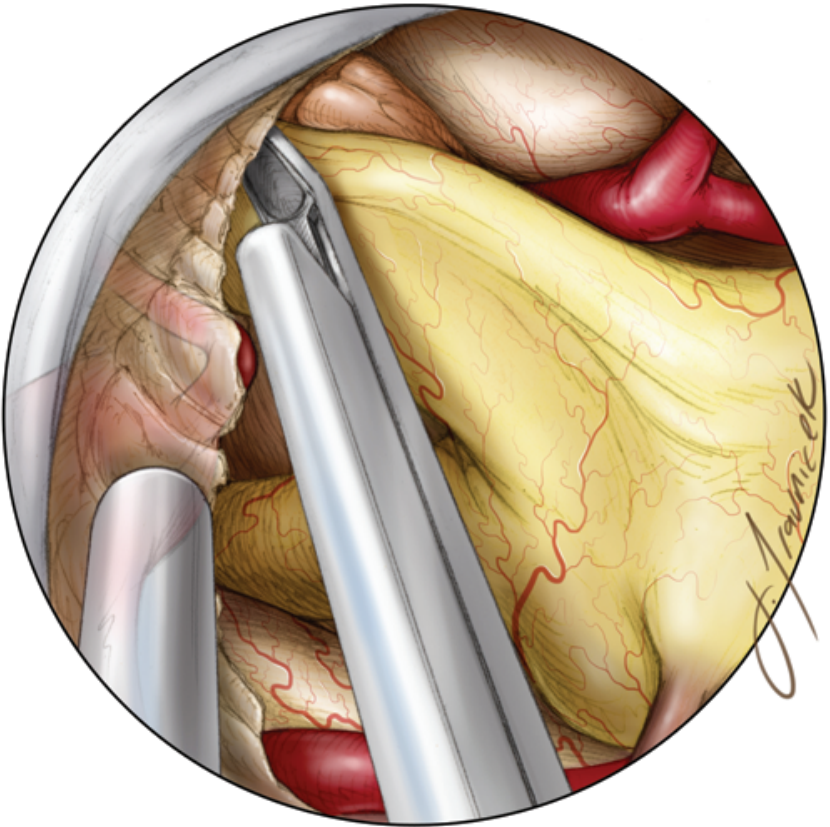

FIG. 10. Dural opening of the optic canals. A sickle knife is used to open the dura of the optic canal. The opening is made superiorly to avoid the inferomedial ophthalmic artery. If the artery cannot be visualized, a micro-Doppler ultrasonography probe can be used to identify its location. Reproduced with permission from Aaron A. Cohen-Gadol: The Neurosurgical Atlas.

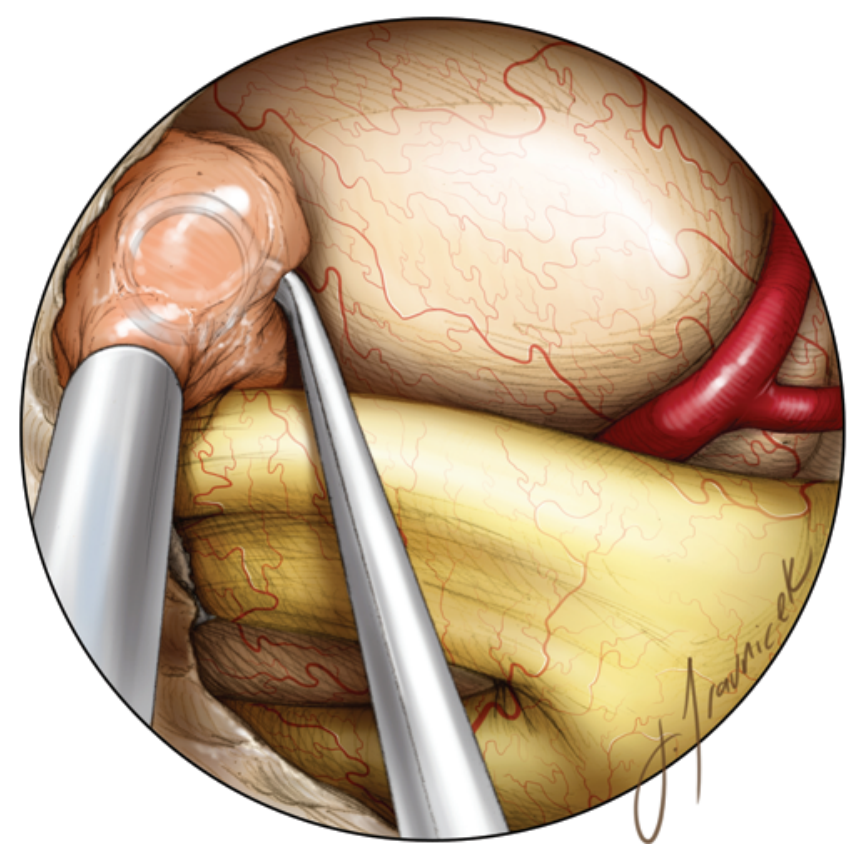

Fig. 11. Tumor removal from the optic canals. The canals can now be fully visualized, and any tumor can be carefully dissected off the nerves and resected. To avoid nerve retraction against the dural edge during tumor dissection, the operator should not attempt tumor removal until the canal dura has been fully opened. Reproduced with permission from Aaron A. Cohen-Gadol: The Neurosurgical Atlas. 


\section{Kulwin, T. H. Schwartz, and A. A. Cohen-Gadol}

\section{Step 6: Closure}

After irrigation and hemostasis, a gasket closure technique with a dural substitute or fascia lata that is circumferentially at least $1 \mathrm{~cm}$ larger than the bony defect is used. This layer of tissue is countersunk and held in place by a Porex rigid implant (Stryker Corporation) cut to the appropriate size (Fig. 12). ${ }^{8,16}$ To avoid optic nerve compression by the prosthetic, the operator should make lateral slits in the rigid implant. To avoid any unintended optic nerve compression and to facilitate interpretation of postoperative images, we do not pack the sella or tumor cavity with foreign material. Some authors recommend an inlay of DuraGen (Integra LifeSciences Corporation) or DURAFORM (DePuy Synthes) to reconstruct the pial plane; we have not found this maneuver to be necessary. The nasoseptal flap is placed over the gasket seal; the lateral edges of the flap should extend beyond the lateral edges of the fascia lata layer. The flap is then covered with tissue sealant, either fibrin glue or DuraSeal (Covidien) to keep it in place. Floseal (Baxter) is then used to control mucosal bleeding. Nasal gauze or tampons can be placed to control nasal discharge in the immediate postoperative period. To facilitate early patient mobilization, if a lumbar drain has been used, we prefer to leave it in place for only 24 hours.

\section{Discussion}

Numerous large case series describing transcranial approaches to tuberculum sellae meningiomas show the safety and efficacy of this widely used approach. ${ }^{6,19}$ However, despite modern microsurgical techniques, the reported incidence of postoperative visual decline is $10 \%-15 \% .6$ Given that visual decline is the most com-

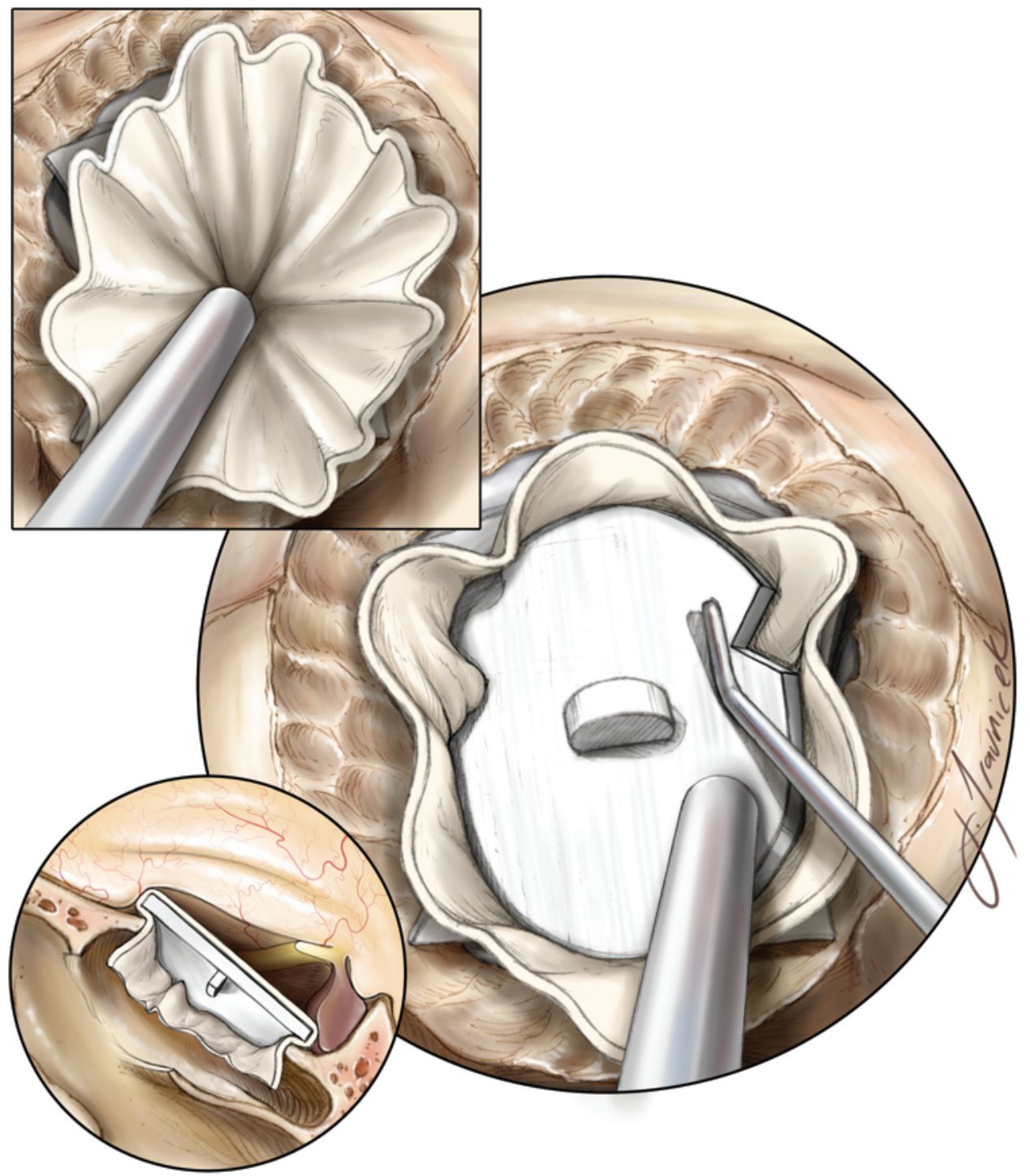

Fig. 12. Gasket-seal closure. Upper: Dura substitute or fascia lata, $1 \mathrm{~cm}$ larger than the dural opening, is countersunk into the skull base defect. Center: A Porex implant with lateral cuts for the optic nerves is wedged into the bony opening to hold the dura substitute in place. L Lower: A lateral view of the finished gasket seal, which is subsequently covered by the nasoseptal flap and tissue sealant. Reproduced with permission from Aaron A. Cohen-Gadol: The Neurosurgical Atlas. 


\section{Endoscopic resection of tuberculum sellae meningiomas}

mon feature of these lesions and that vision preservation or improvement is a key goal of surgery, the risk for postoperative visual deterioration remains a significant concern. ${ }^{19}$ An approach from below, which does not involve retraction of the brain or optic apparatus, is appealing as a way to lower the incidence of visual dysfunction. Recent literature reviews have shown that rates of visual decline after endoscopic endonasal surgery are lower, 2,6 which, although intuitive, is not yet definitive. ${ }^{14}$ However, the biggest criticism of these studies is that surgeons tend to select smaller tumors for endoscopic endonasal resection, which minimizes the likelihood of visual decline. The only way to address this issue would be to study the results of transcranial surgery for tumors that might have been considered for the endonasal approach for direct comparison.

Overall, endoscopic endonasal surgery carries a higher risk for CSF leakage; ${ }^{2,6,14}$ however, this risk decreases markedly with increased experience, especially when a vascularized mucosal flap closure is used. More recent case series have shown that CSF leakage rates of less than $1 \%$, similar to leakage rates after transcranial approaches, can be achieved. ${ }^{18,22}$ As tuberculum sellae meningioma is frequently a small, midline, infrachiasmatic skull base lesion, resection of it through an endoscopic endonasal approach might be a superior option for well-selected cases. The other major criticism is that complete resections cannot be achieved endonasally and that tumor recurrence rates will be higher. This issue needs to be addressed by additional studies with longer follow-up times.

Delineating the role of endoscopic endonasal resection for the treatment of tuberculum sellae meningiomas requires more widespread use, safe application, and careful case selection. To that end, we have presented this technical description. We have described our 6-step approach to tumor resection: wide bony opening in the approach, internal decompression and anterosuperior margin dissection to define the arachnoid plane, inferior margin dissection, lateral tumor removal, optic canal exploration and decompression, and closure. This stepwise approach ensures safety through delineation of anatomic structures, exploration to avoid leaving residual tumor, and minimal manipulation of sensitive neurovascular structures.

\section{Disclosure}

The authors report no conflict of interest concerning the materials or methods used in this study or the findings specified in this paper.

Author contributions to the study and manuscript preparation include the following. Conception and design: Cohen-Gadol, Kulwin, Schwartz. Acquisition of data: Cohen-Gadol, Kulwin, Schwartz. Analysis and interpretation of data: Cohen-Gadol, Kulwin, Schwartz. Drafting the article: Cohen-Gadol, Kulwin, Schwartz. Critically revising the article: all authors. Reviewed submitted version of manuscript: Kulwin, Schwartz. Approved the final version of the manuscript on behalf of all authors: Cohen-Gadol.

\section{References}

1. Attia M, Kandasamy J, Jakimovski D, Bedrosian J, Alimi M, Lee DL, et al: The importance and timing of optic canal ex- ploration and decompression during endoscopic endonasal resection of tuberculum sella and planum sphenoidale meningiomas. Neurosurgery 71 (1 Suppl Operative):58-67, 2012

2. Bohman LE, Stein SC, Newman JG, Palmer JN, Adappa ND, Khan A, et al: Endoscopic versus open resection of tuberculum sellae meningiomas: a decision analysis. ORL J Otorhinolaryngol Relat Spec 74:255-263, 2012

3. Cappabianca P, Cavallo LM, Esposito F, De Divitiis O, Messina A, De Divitiis E: Extended endoscopic endonasal approach to the midline skull base: the evolving role of transsphenoidal surgery. Adv Tech Stand Neurosurg 33:151-199, 2008

4. Cook SW, Smith Z, Kelly DF: Endonasal transsphenoidal removal of tuberculum sellae meningiomas: technical note. Neurosurgery 55:239-246, 2004

5. de Divitiis E, Cappabianca P, Cavallo LM: Endoscopic transsphenoidal approach: adaptability of the procedure to different sellar lesions. Neurosurgery 51:699-707, 2002

6. de Divitiis E, Esposito F, Cappabianca P, Cavallo LM, de Divitiis O: Tuberculum sellae meningiomas: high route or low route? A series of 51 consecutive cases. Neurosurgery 62: $556-563,2008$

7. Frank G, Pasquini E: Tuberculum sellae meningioma: the extended transsphenoidal approach-for the virtuoso only? World Neurosurg 73:625-626, 2010

8. Garcia-Navarro V, Anand VK, Schwartz TH: Gasket seal closure for extended endonasal endoscopic skull base surgery: efficacy in a large case series. World Neurosurg [epub ahead of print], 2011

9. Gardner PA, Kassam AB, Thomas A, Snyderman CH, Carrau RL, Mintz AH, et al: Endoscopic endonasal resection of anterior cranial base meningiomas. Neurosurgery 63:36-54, 2008

10. Hadad G, Bassagasteguy L, Carrau RL, Mataza JC, Kassam A, Snyderman $\mathrm{CH}$, et al: A novel reconstructive technique after endoscopic expanded endonasal approaches: vascular pedicle nasoseptal flap. Laryngoscope 116:1882-1886, 2006

11. Jho HD: Endoscopic endonasal approach to the optic nerve: a technical note. Minim Invasive Neurosurg 44:190-193, 2001

12. Jho HD: Endoscopic transsphenoidal surgery. J Neurooncol 54:187-195, 2001

13. Koc K, Anik I, Ozdamar D, Cabuk B, Keskin G, Ceylan S: The learning curve in endoscopic pituitary surgery and our experience. Neurosurg Rev 29:298-305, 2006 (Erratum in Neurosurg Rev 30:96, 2007)

14. Komotar RJ, Starke RM, Raper DM, Anand VK, Schwartz TH: Endoscopic endonasal versus open repair of anterior skull base CSF leak, meningocele, and encephalocele: a systematic review of outcomes. J Neurol Surg A Cent Eur Neurosurg 74:239-250, 2013

15. Laufer I, Anand VK, Schwartz TH: Endoscopic, endonasal extended transsphenoidal, transplanum transtuberculum approach for resection of suprasellar lesions. J Neurosurg 106: 400-406, 2007

16. Leng LZ, Brown S, Anand VK, Schwartz TH: "Gasket-seal" watertight closure in minimal-access endoscopic cranial base surgery. Neurosurgery 62 (5 Suppl 2):ONSE342-ONSE343, 2008

17. Liu JK, Christiano LD, Patel SK, Tubbs RS, Eloy JA: Surgical nuances for removal of tuberculum sellae meningiomas with optic canal involvement using the endoscopic endonasal extended transsphenoidal transplanum transtuberculum approach. Neurosurg Focus 30(5):E2, 2011

18. Mascarenhas L, Moshel YA, Bayad F, Szentirmai O, Salek AA, Leng LZ, et al: The transplanum transtuberculum approaches for suprasellar and sellar-suprasellar lesions: avoidance of cerebrospinal fluid leak and lessons learned. World Neurosurg [epub ahead of print], 2013

19. Nakamura M, Roser F, Struck M, Vorkapic P, Samii M: Tuber- 


\section{Kulwin, T. H. Schwartz, and A. A. Cohen-Gadol}

culum sellae meningiomas: clinical outcome considering different surgical approaches. Neurosurgery 59:1019-1029, 2006

20. O'Malley BW Jr, Grady MS, Gabel BC, Cohen MA, Heuer GG, Pisapia J, et al: Comparison of endoscopic and microscopic removal of pituitary adenomas: single-surgeon experience and the learning curve. Neurosurg Focus 25(6):E10, 2008

21. Padhye V, Naidoo Y, Alexander H, Floreani S, Robinson S, Santoreneos S, et al: Endoscopic endonasal resection of anterior skull base meningiomas. Otolaryngol Head Neck Surg 147:575-582, 2012

22. Patel KS, Komotar RJ, Szentirmai O, Moussazadeh N, Raper DM, Starke RM, et al: Case-specific protocol to reduce cerebrospinal fluid leakage after endonasal endoscopic surgery. Clinical article. J Neurosurg 119:661-668, 2013

23. Rubin G, Ben David U, Gornish M, Rappaport ZH: Meningiomas of the anterior cranial fossa floor. Review of 67 cases. Acta Neurochir (Wien) 129:26-30, 1994

24. Sekhar L, Janecka I: Surgery of Cranial Base Tumors. New York: Raven Press, 1993

25. Smith SJ, Eralil G, Woon K, Sama A, Dow G, Robertson I: Light at the end of the tunnel: the learning curve associated with endoscopic transsphenoidal skull base surgery. Skull Base 20:69-74, 2010
26. Snyderman CH, Pant H, Carrau RL, Prevedello D, Gardner P, Kassam AB: What are the limits of endoscopic sinus surgery?: the expanded endonasal approach to the skull base. Keio J Med 58:152-160, 2009

27. Wang Q, Lu XJ, Ji WY, Yan ZC, Xu J, Ding YS, et al: Visual outcome after extended endoscopic endonasal transsphenoidal surgery for tuberculum sellae meningiomas. World Neurosurg 73:694-700, 2010

28. Zada G, Kelly DF, Cohan P, Wang C, Swerdloff R: Endonasal transsphenoidal approach for pituitary adenomas and other sellar lesions: an assessment of efficacy, safety, and patient impressions. J Neurosurg 98:350-358, 2003

Manuscript submitted August 14, 2013.

Accepted August 30, 2013.

Please include this information when citing this paper: DOI: 10.3171/2013.8.FOCUS13338.

Address correspondence to: Aaron A. Cohen-Gadol, M.D., M.Sc., Goodman Campbell Brain and Spine, Department of Neurological Surgery, Indiana University School of Medicine, Ste. 5100, 355 W. 16th St., Indianapolis, IN 46202. email: acohenmd@gmail.com. 